\title{
Dronedarone attenuates the duration of atrial fibrillation in a dog model of sustained atrial fibrillation
}

\author{
Nakkawee SAENGKLUB ${ }^{1)}$, Vudhiporn LIMPRASUTR ${ }^{2)}$, Suwanakiet SAWANGKOON ${ }^{2}$, \\ Robert L. HAMLIN ${ }^{3)}$, and Anusak KIJTAWORNRAT ${ }^{2,4)}$ \\ 1) Animal Physiology Program, Faculty of Veterinary Science, Chulalongkorn University, 39 Henri Dunant Road, \\ Pathumwan, Bangkok 10330, Thailand \\ 2) Department of Physiology, Faculty of Veterinary Science, Chulalongkorn University, 39 Henri Dunant Road, \\ Pathumwan, Bangkok 10330, Thailand \\ 3) QTest Labs, Ltd., 6456 Fiesta Drive, Columbus, Ohio 43235, USA \\ 4) Research clusters: research study and testing of drug's effect related to cardiovascular system in laboratory \\ animal, Chulalongkorn University, 39 Henri Dunant Road, Pathumwan, Bangkok 10330, Thailand
}

\begin{abstract}
Atrial fibrillation (AF) is a supraventricular arrhythmia that leads to a decrease in cardiac output and impairs cardiac function and quality of life. Dronedarone has an atrial-selective property and has been used for management of AF in humans, but limited information is available in dogs. This study was designed to evaluate efficacy of dronedarone in attenuating the duration of AF in dog model of sustained AF. Six beagle dogs were anesthetized with isoflurane and instrumented to measure atrial action potential duration (aAPD) and atrial effective refractory period (AERP). Then AF was induced by rapid right atrial pacing $(20 \mathrm{~V}, 40 \mathrm{~Hz})$ simultaneously with infusion of phenylephrine ( $2 \mu \mathrm{g} / \mathrm{kg} / \mathrm{min}$, intravenously) for $20 \mathrm{~min}$. The duration of sustained AF was recorded, and the animals were allowed to recover. Dronedarone was given at a dose of $20 \mathrm{mg} / \mathrm{kg}$, BID, orally for 7 days. On the last day, the dogs were anesthetized again to record AAPD and AERP, and AF was induced with the same procedure as described above. The results showed that after dronedarone administration the aAPD was lengthened significantly from $76.4 \pm 4.2 \mathrm{~ms}$ to $91.2 \pm 3.9 \mathrm{~ms}(P<0.05)$ and AERP was prolonged significantly from $97.5 \pm 2.8 \mathrm{~ms}$ to $120 \pm 4.8 \mathrm{~ms}(P<0.05)$. The duration of sustained AF was also significantly attenuated after receipt of dronedarone $(P<0.05)$. It can be suggested that oral dronedarone attenuates the duration of sustained $A F$ in a dog model of $A F$ by extending the AERP more than the aAPD, causing post-repolarization refractoriness. Hence, dronedarone may be useful for management of $A F$ in dogs.
\end{abstract}

Key words: atrial fibrillation, dog, dronedarone, post-repolarization refractoriness

\section{Introduction}

Atrial fibrillation (AF) is a form of supraventricular arrhythmias. Its prevalence has been observed in large and giant breeds (i.e., Irish Wolfhound, Great Dane, Newfoundland, and Doberman pinscher) and small breeds with underlying heart diseases [14, 23, 37]. The consequences of AF are decreased cardiac output and impaired mechanical function of the heart and quality of life [32]. Rhythm control and rate control strategies have been suggested for management of AF in dogs [32]. In clinical practice, rhythm control either by electrical car-

(Received 5 January 2017 / Accepted 15 March 2017 / Published online in J-STAGE 4 April 2017)

Address corresponding: A. Kijtawornrat, Department of Physiology, Faculty of Veterinary Science, Chulalongkorn University, 39 Henri Dunant

Road, Pathumwan, Bangkok 10330, Thailand

(C)2017 Japanese Association for Laboratory Animal Science 
dioversion or by pharmacological conversion has demonstrated more risk to patients than control of the ventricular response rate due to the need for general anesthesia and pharmacological side effects [9]. Therefore, rate control strategy is preferred by several practitioners. Besides digoxin, diltiazem, quinidine, and atenolol, amiodarone has been used widely in veterinary medicine since it was demonstrated to restore sinus rhythm and reduce ventricular response rate in dogs with AF $[17,26,28,33]$. Similar to in humans, the adverse effects of these antiarrhythmic drugs have been reported in $\operatorname{dogs}[1,2,16,28,33]$.

Dronedarone, a class III antiarrhythmic drug, has been approved for management of AF in humans by FDA since 2009 [24, 34]. Several clinical trials have been demonstrated the advantages of dronedarone in restoring sinus rhythm as well as controlling ventricular response rate in AF patients without heart failure [15, 20, 35, 36]. Furthermore, dronedarone prevents AF recurrences and prolongs the time to onset of first AF occurrence in patients at high risk of AF [27]. Our previous study in anesthetized dogs showed that dronedarone reduced the heart rate and lengthened the PQ interval [30]. A study in conscious dogs instrumented with telemetry units showed that dronedarone $(20 \mathrm{mg} / \mathrm{kg}$, twice a day (BID), orally) prolonged the PQ interval without effects on cardiac inotropy and lusitropy [31]. It has been reported in canine isolated coronary-perfused atria that the efficacy of acute dronedarone $(10 \mu \mathrm{mol} / \mathrm{l})$ in preventing AF induced by acetylcholine infusion and terminating persistent $\mathrm{AF}$ is poor when compared with amiodarone [6]. However, previous data in anesthetized dogs indicated that acute administration of dronedarone resulted in electrophysiological actions similar to those produced by amiodarone [21]. Since the efficacy of dronedarone is controversial, the efficacy of dronedarone in management of AF in vivo should be confirmed. In addition, the adverse effect of dronedarone at a therapeutic dose has not been established in dogs. This study was designed to 1) evaluate effects of oral dronedarone on prevention of atrial fibrillation and 2) investigate its mechanism of prevention related to atrial electrophysiology in a dog model of sustained atrial fibrillation. This experiment may support the use of dronedarone for management of $\mathrm{AF}$ in clinical AF dogs.

\section{Materials and Methods}

\section{Approvals}

This study was approved by the Institutional Animal Care and Use Committee of QTest Labs, Ltd., Columbus, OH, USA (protocol number: SPD14-022). All experimental animal procedures were performed in compliance with QTest Institutional Animal Care and Use Committee regulations, and followed the guidelines outlined in the Guide for the Care and Use of Laboratory Animals [25].

\section{Animals}

Six healthy mature beagles (Canis familiaris) of either gender were purchased from Marshall BioResources (North Rose, NY, USA). They were housed individually from the time of arrival to the end of the study in a dog run maintained at a temperature of $21 \pm 2^{\circ} \mathrm{C}$ and a relative humidity of $50 \pm 20 \%$, with a $12 \mathrm{~h}: 12 \mathrm{~h}$ light:dark cycle. All animals were received commercial chow twice daily, and water was provided ad libitum in stainless steel containers. Physical examination, routine lead II electrocardiogram (ECG) recording, complete blood count, and blood chemistry analysis were performed to evaluate healthy status in all dogs before the beginning of the experiment. Surgical procedures were started a fasting period of at least $6 \mathrm{~h}$ period of fasting.

Surgical procedures for measurement of atrial effective refractory period (AERP), atrial action potential duration (aAPD), and induction of sustained $A F$

All dogs were given butorphanol $(0.1 \mathrm{mg} / \mathrm{kg}$, intravenously) $10 \mathrm{~min}$ before receiving propofol $(4-6 \mathrm{mg} / \mathrm{kg}$, intravenously). Orotracheal intubation was performed and ventilated mechanically with an ascending-bellows, volume-cycled, pressure-regulated ventilator. The ventilator was set to deliver a tidal volume of $12-15 \mathrm{ml} / \mathrm{kg}$ (maximum allowed pressure, $20 \mathrm{cmH}_{2} \mathrm{O}$ ) at a rate of 8 to 12 breaths per min, sustaining the end-tidal partial pressure of $\mathrm{CO}_{2}$ between 35 and $45 \mathrm{mmHg}$ and that of $\mathrm{O}_{2}$ greater than $80 \mathrm{mmHg}$. The endotracheal tube was connected to a circle anesthetic rebreathing circuit, and anesthesia was maintained with isoflurane in oxygen delivered by a use of vaporizer. The end-tidal inhalant concentration was maintained between 1.4-1.6\%. Body temperature was maintained at $36.5-37^{\circ} \mathrm{C}$ by a warm water heating pump. Each animal was shaved and scrubbed at the surgical areas and prepared by aseptic 
technique (left femoral triangle and left jugular area).

A Mikro-Tip catheter pressure transducer (5Fr, Millar, Inc., Houston, TX, USA) was inserted into the left femoral artery and advanced to the aortic arch for measuring systemic arterial blood pressure. With the help of fluoroscope guidance, a monophasic action potential catheter was inserted through the left jugular vein and pushed against the endocardium of the right atrium to obtain the aAPD. AERP was obtained by using a programmable electrical stimulator. Extrastimuli were introduced at premature coupling intervals $\left(\mathrm{S}_{1}-\mathrm{S}_{2}\right)$ by progressively shortening by $10 \mathrm{~ms}$ the pacing cycle length until atria failed to depolarize. Then, the pacing cycle length was progressively increased by $5 \mathrm{~ms}$ until it caused atrial depolarization. The AERP was the longest $\mathrm{S}_{1}-\mathrm{S}_{2}$ interval that failed to cause atrial depolarization.

Lead II ECG data were monitored for rhythm and rate. After obtaining the aAPD and AERP, a bipolar pacing catheter was positioned at the right atrial appendage through the left jugular vein for induction of AF. Sustained AF was induced according to the method in a previous publication [18]. Briefly, the right atrial appendage was pacing at a rate of $40 \mathrm{~Hz}$ with square waves of $20 \mathrm{~V}$ and $2 \mathrm{~ms}$ duration. Simultaneously, phenylephrine (PE, $2 \mu \mathrm{g} / \mathrm{kg} / \mathrm{min}$ ) (Baxter Healthcare Corporation, Deerfield, IL, USA) was infused constantly through a peripheral intravenous catheter placed inside the right cephalic vein until the end of the session. After $20 \mathrm{~min}$ of rapid atrial pacing (RAP), the pacing was stopped, and the duration of AF was observed. AF was identified by (1) the presence of an irregular rapid ventricular response, (2) absence of a P wave, (3) presence of lowfrequency irregular oscillations (f waves), and (4) a presence of irregular systemic arterial pressure pulses that were variable in amplitude and had a pulse deficit. At the end of experiment, all vessels were sutured with 8-0 Prolene. Tissues and muscles were sutured with absorbable 3-0 suture materials. Skin was closed with sterile staples. Butorphanol $(0.05-0.4 \mathrm{mg} / \mathrm{kg}$, once a day, subcutaneously; Abbott Laboratories, North Chicago, IL, USA), acepromazine $(0.05-0.2 \mathrm{mg} / \mathrm{kg}$, once a day, subcutaneously; Butler Animal Health Supply, Dublin, $\mathrm{OH}, \mathrm{USA})$, and cefazolin (15 mg/kg, once a day, subcutaneously; Butler Animal Health Supply, Dublin, $\mathrm{OH}$, USA) were administered for 7 days.

\section{Experimental procedures}

After instrumentation, dogs were allowed to stabilize for at least $30 \mathrm{~min}$. Then ECG, blood pressure (BP), aAPD, and AERP data were obtained. After all data were collected, sustained AF was induced. The incidence and duration of AF were recorded after pacing was stopped. The dogs were allowed to recover, and dronedarone (20 $\mathrm{mg} / \mathrm{kg}$, BID, orally) was given for 7 days beginning the next day. The dose of dronedarone was chosen based on our previous experiment in conscious dogs instrumented with a telemetry unit [31]. After 7 days of drug administration, the dogs were anesthetized and instrumented as described earlier for obtaining ECG, BP, aAPD, and AERP data. Each dog was infused with PE at a dose of $2 \mu \mathrm{g} / \mathrm{kg} / \mathrm{min}$. Simultaneously, RAP was initiated as described earlier. After $20 \mathrm{~min}$ of pacing, pacing was stopped, and the cardiac rhythm was monitored. Then, the concentration of PE was increased to $4 \mu \mathrm{g} / \mathrm{kg} / \mathrm{min}$, and the atrium was paced again for $20 \mathrm{~min}$. At the end of the experiment, all animals were allowed to recover, and postoperative care was performed for 7 days. Then all dogs were transferred back to the in-house colony.

\section{Data analysis}

ECG and BP were analyzed for heart rate (HR) or ventricular response rate (VR) and mean blood pressure (MBP) before dosing (at baseline before PE infusion with RAP and at 20 min during PE infusion with RAP) and 7 days after dosing (at baseline, at $20 \mathrm{~min}$ in the first trial during PE infusion [ $2 \mu \mathrm{g} / \mathrm{kg} / \mathrm{min}$ ] with RAP, and at $20 \mathrm{~min}$ in the second trial of PE infusion $[4 \mu \mathrm{g} / \mathrm{kg} / \mathrm{min}$ ] with RAP] by using the ecgAuto software (EMKA Technologies, Falls Church, VA, USA). APD 70 was defined as the action potential duration at $70 \%$ repolarization of the aAPD. The $\mathrm{APD}_{70}$ and AERP were obtained before dosing and 7 day after dosing. Post-repolarization refractoriness (PRR) was calculated as the percent change of differences between the AERP and atrial $\mathrm{APD}_{70}$. In atria, the AERP usually coincided with $\mathrm{APD}_{70}$ to $\mathrm{APD}_{75}$ [7]. The duration of sustained AF after dosing was calculated as the averaged of the duration of AF from the first and second trials.

\section{Statistical analysis}

Statistical analyses were performed with commercially available software. Data were presented as the mean \pm standard error of the mean. All data points were averaged from $60 \mathrm{~s}$ of recording. Differences between before dosing and after dosing were determined by paired $t$-test. The percent change from before dosing was 


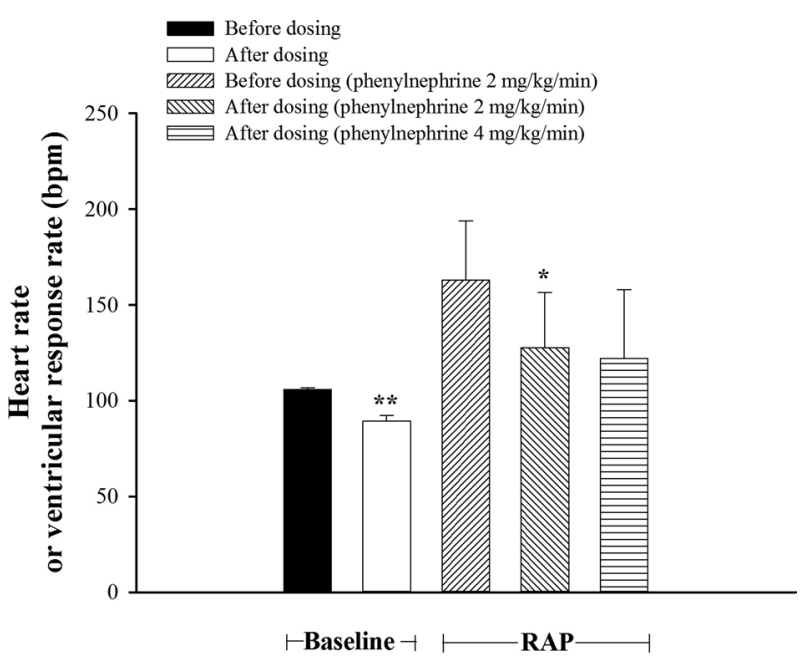

Fig. 1. Plots of heart rate (at baseline before the beginning of phenylephrine infusion) and ventricular response rate (during rapid atrial pacing, RAP) for before and after dosing with oral dronedarone administration $(20 \mathrm{mg} / \mathrm{kg}$, BID) for 7 days in dogs while they were anesthetized with isoflurane. *Significant difference when compared with the ventricular response (VR) during phenylephrine (PE) infusion simultaneous to RAP before dosing $(P<0.05)$. **Significant difference when compared with before dosing at baseline $(P<0.01)$.

calculated for the PRR parameter, and the difference was determined by Student's $t$-test. Fisher's exact tests were used to compare the incidence of reduction of AF duration between before and after dosing. A probability value of $P<0.05$ was considered to be significant.

\section{Results}

Before the onset of PE infusion (baseline) while the dogs were anesthetized, HR and MBP (before dosing) were $106 \pm 1.0$ beats per min (bpm) and $69.7 \pm 1.7$ $\mathrm{mmHg}$, respectively (Figs. 1 and 2). After oral dronedarone administration (20 mg/kg, BID) for 7 days, HR and MBP were significantly reduced $(P<0.05)$, by $15.6 \%$ and $14.0 \%$, respectively, when compared with before dosing. During RAP performed simultaneous to PE infusion before dosing, VR was $163 \pm 31 \mathrm{bpm}$. After dosing, VR during RAP and PE infusion at $2 \mu \mathrm{g} / \mathrm{kg} / \mathrm{min}$ declined significantly $(21.6 \%, P<0.05)$, while VR during RAP and $P E$ infusion at $4 \mu \mathrm{g} / \mathrm{kg} / \mathrm{min}$ did not change when compared with that before dosing (Fig. 1). MBP before dosing was $137.2 \pm 15.4 \mathrm{mmHg}$. After dosing, neither MBP during RAP and PE infusion at $2 \mu \mathrm{g} / \mathrm{kg} / \mathrm{min}$ nor MBP during RAP and PE infusion at $4 \mu \mathrm{g} / \mathrm{kg} / \mathrm{min}$ were

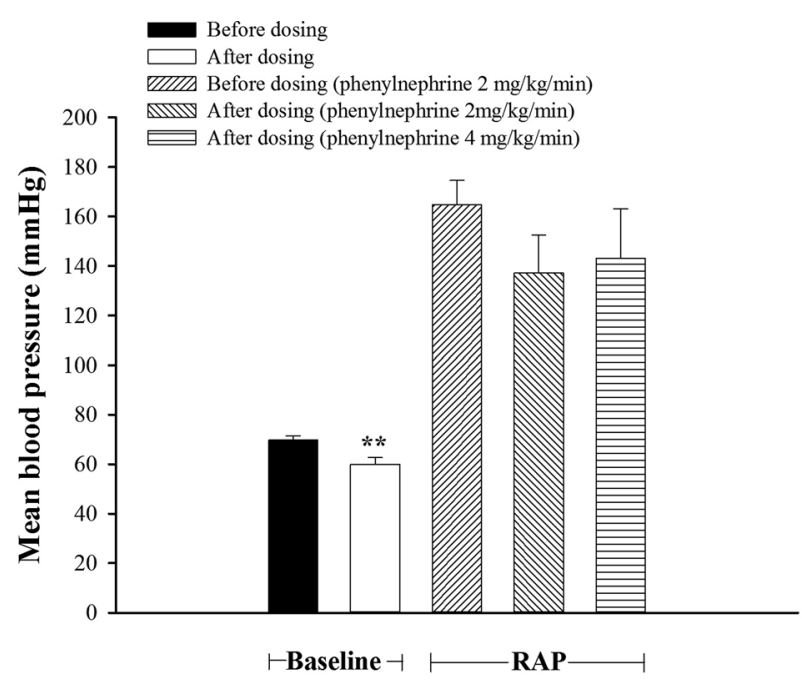

Fig. 2. Plots of mean blood pressure at baseline (before the beginning of phenylephrine infusion) and rapid atrial pacing (RAP) for before and after dosing with oral dronedarone $(20 \mathrm{mg} / \mathrm{kg}$, BID) for 7 days in dogs while they were anesthetized with isoflurane. ${ }^{* *}$ Significant difference when compared with before dosing at baseline $(P<0.01)$

different from MBP during RAP and PE infusion before dosing (Fig. 2).

In response to dronedarone, the $\mathrm{APD}_{70}$ of the atrium showed a significant increase of $19.3 \%$ compared with that before dosing (before dosing, $76.4 \pm 4.2 \mathrm{~ms}$ vs. after dosing; after dosing, $91.2 \pm 3.9 \mathrm{~ms} ; P<0.001)$. The AERP also showed a significant increase, increasing $23.1 \%$ compared with that before dosing (before dosing, 97.5 $\pm 2.8 \mathrm{~ms}$; after dosing, $120.0 \pm 4.8 ; P<0.01)$. Hence, PRR showed a significant increase of $36.7 \%$ compared with before dosing (from $21.1 \pm 4.6 \mathrm{~ms}$ to $28.8 \pm 6.4 \mathrm{~ms}$; $P<0.05)$.

Before dosing, atrial fibrillation persisted after PE infusion and RAP in all dogs for an average of $88.8 \mathrm{~s}$ (ranging from 441.7 to $1.89 \mathrm{~s}$ ) after cessation of pacing (Fig. 3). After 7 days of dronedarone administration, sustained AF was induced in 5 dogs in which the average duration of sustained AF was reduced to $5.7 \mathrm{~s}$ (ranging from 4.3 to $10.7 \mathrm{~s}$ ). While it was not possible to induce sustained AF in one dog (Fig. 4), the duration of sustained AF was increased in one dog (from 1.9 to $5.8 \mathrm{~s}$ ). Therefore, the overall percentage of dogs in which dronedarone attenuated the duration of AF in dogs model of sustained AF was $83.3 \%$ (5/6 dogs, $P<0.05)$. 


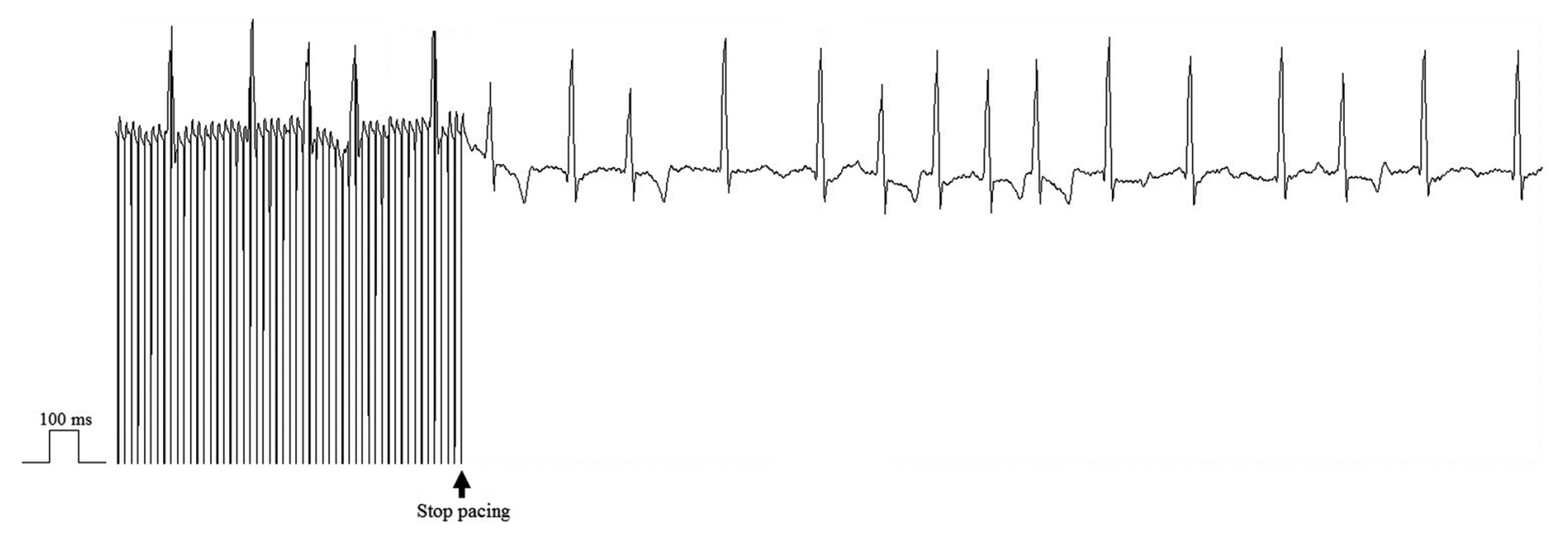

Fig. 3. Lead II electrocardiogram in an anesthetized dog with rapid atrial pacing ( $40 \mathrm{~Hz}, 20 \mathrm{~V}$, and $2 \mathrm{~ms}$ ) and phenylephrine infusion ( $2 \mu \mathrm{g} / \mathrm{kg} / \mathrm{min}$ ). Atrial fibrillation characterized by fibrillatory waves that varied in amplitude, shape, and timing occurred after cessation of rapid atrial pacing.

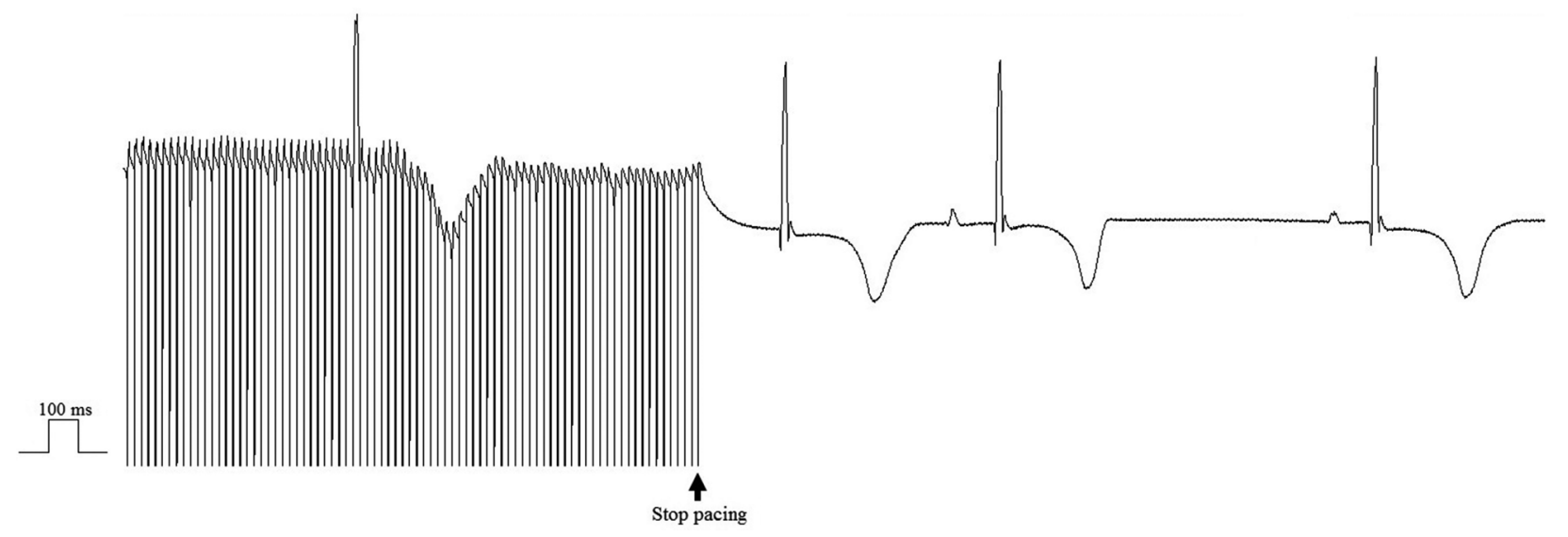

Fig. 4. Lead II electrocardiogram in an anesthetized dog treated with dronedarone ( $20 \mathrm{mg} / \mathrm{kg}$, BID, orally) for 7 days. Atrial fibrillation was induced by rapid atrial pacing $(40 \mathrm{~Hz}, 20 \mathrm{~V}$, and $2 \mathrm{~ms})$ and phenylephrine infusion $(2 \mu \mathrm{g} / \mathrm{kg} / \mathrm{min})$, and it was converted to normal sinus rhythm soon after rapid atrial pacing was stopped.

\section{Discussion}

The present study demonstrated that dronedarone was effective against experimentally induced sustained AF. The sustained AF used in this study was induced by RAP with simultaneous PE infusion. According to a previous publication, PE was used to elevate systemic arterial pressure, which would increase stimulation of vagal efferents via the baroreceptor reflex [18]. Since vagal fibers in atria are heterogeneously distributed, stimulation of the vagus nerve creates heterogeneity of repolarization, which contributes to AF.

The present study also showed that dronedarone produces a reduction in heart rate in anesthetized dogs both at baseline (before the onset of RAP) and after RAP with
PE infusion ( $2 \mu \mathrm{g} / \mathrm{kg} / \mathrm{min})$. This effect was consistent with our previous study in isoflurane-anesthetized dogs and in conscious dogs instrumented with telemetry units [31]. The efficacy of dronedarone in reducing the ventricular rate was also observed in patients with permanent AF both at rest and during exercise [10]. It has been shown previously that dronedarone exerts a bradycardia effect with different combinations of inhibition of pacemaker current and blockade of $\beta$-adrenergic receptor and calcium channels $[4,8,13,29]$. Heart rate reduction is the therapeutic target in patients with heart disease, including patients with AF, since an elevated HR results in increased myocardium oxygen demand and energy depletion, which aggravates heart function. Therefore, the reduction of HR and VR caused by dronedarone in 
AF dogs might preserve the cardiac function and reduce the risk of development of congestive heart failure.

Dronedarone has been reported to prevent and terminate $\mathrm{AF}$ in previous in vitro models $[6,7]$. In canine isolated arterially perfused right atria, acute dronedarone $(10 \mu \mathrm{M})$ prevents acetylcholine-mediated AF and terminates persistent AF [6]. Furthermore, a combination of dronedarone $(10 \mu \mathrm{mol} / \mathrm{l})$ and ranolazine $(5 \mu \mathrm{mol} / \mathrm{l})$ has been shown to prevent the induction of AF in canine isolated coronary-perfused right and left atria [7]. In this study, AF was induced in all dogs before receipt of dronedarone. After treatment, dronedarone was shown to reduce the duration of AF in 5 of 6 dogs in which one of those 5 dogs was unable to induce AF at all. Thus, our data on the management of AF are generally consistent with those reported previously. The mechanisms by which dronedarone reduced the duration of sustained AF in our study may be due to its effects on the APD of the atria and its effects on the AERP. In this study, dronedarone increased atrial APD 19.3\%, which was less than its effect on the AERP (increased 23.1\%), so PRR developed. The development of PRR was inconsistent with a previous study [7]. In canine right atrial preparations, dronedarone has been shown to alter the aAPD minimally, while its effect on the AERP was markedly lengthened, leading to development of PRR [7]. Bogdan and colleagues [4] suggested that dronedarone exhibits PRR by the state-dependent blockage of fast $\mathrm{Na}^{+}$channels in which a marked inhibition happens at a more depolarized holding potential. This effect could imply that dronedarone possesses an atrial-selective effect. It has been known that atrial cells have intrinsically a more depolarized resting membrane potential (RMP) than ventricular cells $[3,5]$. Furthermore, when the shape of the aAPD is compared with the shape of the ventricular APD, the aAPD has slow phase 3 repolarization; therefore, atrial $\mathrm{Na}^{+}$channels will rest in the inactivated state for a longer time than ventricular $\mathrm{Na}^{+}$channels [4]. Dronedarone and amiodarone, a structurally related compound, have been demonstrated to preferentially block $\mathrm{Na}^{+}$channels in an inactive state [11]. A previous study also showed that a multichannel blocking drug like amiodarone but not a pure potassium channel blocker like $d$-sotalol suppressed excitability during the late repolarization phase in humans [12]. Studies of Maruyama and colleagues (1995) and Kirchhof et al. (2003) have also supported that the additional sodium blocking effect of amiodarone might be responsible for PRR [19, 22].

\section{Study limitations}

All investigations of the present study were performed in anesthetized healthy dogs. In clinical practice, however, dogs with AF almost always have underlying heart diseases. Therefore, extrapolations of results obtained from this study to the clinic should be done with caution.

\section{Conflict of Interest}

The authors declare that they have no conflicts of interest.

\section{Acknowledgments}

This study was supported by the Ratchadaphisek Sompot Endowment Fund of Chulalongkorn University (the 72th and 90th Anniversary of Chulalongkorn University Fund (GCUGR1125572059D); Special Task Force for Activating Research (GSTAR 59-002-31-002)) and QTest Labs, Ltd. Dr. Nakkawee Saengklub was partly supported by the Graduate School, Chulalongkorn University, so that she could perform research while at QTest Labs. We would like to thank Drs. Carlos del Rio and Yukie Ueyama at QTest Labs for their help with equipment setup.

\section{References}

1. Bicer, S., Fuller, G.A., Wilkie, D.A., Yamaguchi, M., and Hamlin, R.L. 2002. Amiodarone-induced keratopathy in healthy dogs. Vet. Ophthalmol. 5: 35-38. [Medline] [CrossRef]

2. Bicer, S., Nakayama, T., and Hamlin, R.L. 2002. Effects of chronic oral amiodarone on left ventricular function, ECGs, serum chemistries, and exercise tolerance in healthy dogs. $J$. Vet. Intern. Med. 16: 247-254. [Medline] [CrossRef]

3. Bogdan, R., Goegelein, H., and Ruetten, H. 2009. Viable heart slices: action potential recordings from atrial and ventricular tissues. Acta Physiol. (Oxf.) 195:(suppl. 669): 64.

4. Bogdan, R., Goegelein, H., and Ruetten, H. 2011. Effect of dronedarone on $\mathrm{Na}+, \mathrm{Ca} 2+$ and $\mathrm{HCN}$ channels. Naunyn Schmiedebergs Arch. Pharmacol. 383: 347-356. [Medline] [CrossRef]

5. Burashnikov, A., Di Diego, J.M., Zygmunt, A.C., Belardinelli, L., and Antzelevitch, C. 2007. Atrium-selective sodium channel block as a strategy for suppression of atrial fibrillation: differences in sodium channel inactivation between atria and ventricles and the role of ranolazine. Circulation 116: 1449-1457. [Medline] [CrossRef]

6. Burashnikov, A., Belardinelli, L., and Antzelevitch, C. 2010. Acute dronedarone is inferior to amiodarone in terminating and preventing atrial fibrillation in canine atria. Heart 
Rhythm 7: 1273-1279. [Medline] [CrossRef]

7. Burashnikov, A., Sicouri, S., Di Diego, J.M., Belardinelli, L., and Antzelevitch, C. 2010. Synergistic effect of the combination of ranolazine and dronedarone to suppress atrial fibrillation. J. Am. Coll. Cardiol. 56: 1216-1224. [Medline] [CrossRef]

8. Chatelain, P., Meysmans, L., Mattéazzi, J.R., Beaufort, P., and Clinet, M. 1995. Interaction of the antiarrhythmic agents SR 33589 and amiodarone with the beta-adrenoceptor and adenylate cyclase in rat heart. Br. J. Pharmacol. 116: 19491956. [Medline] [CrossRef]

9. Crijns, H.J. 2005. Rate versus rhythm control in patients with atrial fibrillation: what the trials really say. Drugs 65 : 1651-1667. [Medline] [CrossRef]

10. Davy, J. M., Herold, M., Hoglund, C., Timmermans, A., Alings, A., Radzik, D., Van Kempen, L. and Investigators, E. S. 2008. Dronedarone for the control of ventricular rate in permanent atrial fibrillation: the Efficacy and safety of dRonedArone for the control of ventricular rate during atrial fibrillation (ERATO) study. Am. Heart J. 156: 527 e521-529.

11. Ehrlich, J.R. and Dobrev, D. 2011. Atrial-selective sodium channel block by dronedarone: sufficient to terminate atrial fibrillation? Naunyn Schmiedebergs Arch. Pharmacol. 384: 109-114. [Medline] [CrossRef]

12. Franz, M.R. and Costard, A. 1988. Frequency-dependent effects of quinidine on the relationship between action potential duration and refractoriness in the canine heart in situ. Circulation 77: 1177-1184. [Medline] [CrossRef]

13. Gautier, P., Guillemare, E., Marion, A., Bertrand, J.P., Tourneur, Y., and Nisato, D. 2003. Electrophysiologic characterization of dronedarone in guinea pig ventricular cells. J. Cardiovasc. Pharmacol. 41: 191-202. [Medline] [CrossRef]

14. Guglielmini, C., Chetboul, V., Pietra, M., Pouchelon, J.L., Capucci, A., and Cipone, M. 2000. Influence of left atrial enlargement and body weight on the development of atrial fibrillation: retrospective study on 205 dogs. Vet. J. 160: 235-241. [Medline] [CrossRef]

15. Hohnloser, S.H., Crijns, H.J., van Eickels, M., Gaudin, C., Page, R.L., Torp-Pedersen, C., Connolly, S.J., Investigators, A., ATHENA Investigators 2010. Dronedarone in patients with congestive heart failure: insights from ATHENA. Eur. Heart J. 31: 1717-1721. [Medline] [CrossRef]

16. Jacobs, G., Calvert, C., and Kraus, M. 2000. Hepatopathy in 4 dogs treated with amiodarone. J. Vet. Intern. Med. 14: 96-99. [Medline] [CrossRef]

17. Johnson, J.T. 1985. Conversion of atrial fibrillation in two dogs using verapamil and supportive treatment. J. Am. Anim. Hosp. Assoc. 21: 429-434.

18. Kijtawornrat, A., Roche, B.M., and Hamlin, R.L. 2008. A canine model of sustained atrial fibrillation induced by rapid atrial pacing and phenylephrine. Comp. Med. 58: 490-493. [Medline]

19. Kirchhof, P., Degen, H., Franz, M.R., Eckardt, L., Fabritz, L., Milberg, P., Läer, S., Neumann, J., Breithardt, G., and Haverkamp, W. 2003. Amiodarone-induced postrepolarization refractoriness suppresses induction of ventricular fibrillation. J. Pharmacol. Exp. Ther. 305: 257-263. [Medline] [CrossRef]
20. Le Heuzey, J.Y., De Ferrari, G.M., Radzik, D., Santini, M., Zhu, J., and Davy, J.M. 2010. A short-term, randomized, double-blind, parallel-group study to evaluate the efficacy and safety of dronedarone versus amiodarone in patients with persistent atrial fibrillation: the DIONYSOS study. $J$. Cardiovasc. Electrophysiol. 21: 597-605. [Medline] [CrossRef]

21. Manning, A., Thisse, V., Hodeige, D., Richard, J., Heyndrickx, J.P., and Chatelain, P. 1995. SR 33589, a new amiodarone-like antiarrhythmic agent: electrophysiological effects in anesthetized dogs. J. Cardiovasc. Pharmacol. 25: 252-261. [Medline] [CrossRef]

22. Maruyama, T., Richardson, L.C., Sun, W., McCarthy, J.J., and Gettes, L.S. 1995. Acute effects of amiodarone on membrane properties, refractoriness, and conduction in guinea pig papillary muscles. Heart Vessels 10: 78-86. [Medline] [CrossRef]

23. Menaut, P., Bélanger, M.C., Beauchamp, G., Ponzio, N.M., and Moïse, N.S. 2005. Atrial fibrillation in dogs with and without structural or functional cardiac disease: A retrospective study of 109 cases. J. Vet. Cardiol. 7: 75-83. [Medline] [CrossRef]

24. Naccarelli, G.V., Wolbrette, D.L., Levin, V., Samii, S., Banchs, J.E., Penny-Peterson, E., and Gonzalez, M.D. 2011. Safety and efficacy of dronedarone in the treatment of atrial fibrillation/flutter. Clin. Med. Insights Cardiol. 5: 103-119. [Medline] [CrossRef]

25. National Research Council. 2011. Guide for the care and use of laboratory animals, 8th ed., National Academies Press, Washington D.C.

26. Oyama, M.A. and Prosek, R. 2006. Acute conversion of atrial fibrillation in two dogs by intravenous amiodarone administration. J. Vet. Intern. Med. 20: 1224-1227. [Medline] [CrossRef]

27. Page, R.L., Connolly, S.J., Crijns, H.J., van Eickels, M., Gaudin, C., Torp-Pedersen, C., Hohnloser, S.H., Investigators, A., ATHENA Investigators 2011. Rhythm- and ratecontrolling effects of dronedarone in patients with atrial fibrillation (from the ATHENA trial). Am. J. Cardiol. 107: 1019-1022. [Medline] [CrossRef]

28. Pyle, R.L. 1967. Conversion of atrial fibrillation with quinidine sulfate in a dog. J. Am. Vet. Med. Assoc. 151: 582-589. [Medline]

29. Rocchetti, M., Bertrand, J.P., Nisato, D., and Guatier, P. 1998. Cellular electrophysiological study of dronedarone, a new amiodarone-like agent, in Guinea pig sinoatrial node. Naunyn Schmiedebergs Arch. Pharmacol. 358:(Suppl 2): R617.

30. Saengklub, N., Limprasutr, V., Sawangkoon, S., Buranakarl, C., Hamlin, R.L., and Kijtawornrat, A. 2016. Acute effects of intravenous dronedarone on electrocardiograms, hemodynamics and cardiac functions in anesthetized dogs. J. Vet. Med. Sci. 78: 177-186 [Medline]

31. Saengklub, N., Youngblood, B., Del Rio, C., Sawangkoon, S., Hamlin, R.L., and Kijtawornrat, A. 2016. Short-term effects of oral dronedarone administration on cardiac function, blood pressure and electrocardiogram in conscious telemetry dogs. J. Vet. Med. Sci. 78: 977-985. [Medline] [CrossRef] 
32. Saunders, A., Gordon, S., and Miller, M. 2009. Canine atrial fibrillation. Compend. Contin. Educ. Vet. 31: E1-E9, quiz E10. [Medline]

33. Saunders, A.B., Miller, M.W., Gordon, S.G., and Van De Wiele, C.M. 2006. Oral amiodarone therapy in dogs with atrial fibrillation. J. Vet. Intern. Med. 20: 921-926. [Medline] [CrossRef]

34. Shaaraoui, M., Freudenberger, R., Levin, V., and Marchlinski, F.E. 2011. Suppression of ventricular tachycardia with dronedarone: a case report. J. Cardiovasc. Electrophysiol. 22: 201-202. [Medline]

35. Singh, B.N., Connolly, S.J., Crijns, H.J., Roy, D., Kowey,
P.R., Capucci, A., Radzik, D., Aliot, E.M., Hohnloser, S.H., EURIDIS and ADONIS Investigators 2007. Dronedarone for maintenance of sinus rhythm in atrial fibrillation or flutter. N. Engl. J. Med. 357: 987-999. [Medline] [CrossRef]

36. Touboul, P., Brugada, J., Capucci, A., Crijns, H.J., Edvardsson, N., and Hohnloser, S.H. 2003. Dronedarone for prevention of atrial fibrillation: a dose-ranging study. Eur. Heart $J$. 24: 1481-1487. [Medline] [CrossRef]

37. Westling, J., Westling, W., and Pyle, R.L. 2008. Epidemiology of atrial fibrillation in the dog. Int. J. Appl. Res. Vet. Med. 6: 151-154. 